\title{
Stercoral perforation of the normal colon: Report of five cases
}

\author{
Department of Emergency Surgery Military Medical Academy Sofia, Bulgaria
}

\begin{abstract}
A series of five consecutive patients with stercoral perforation of the colon is presented. Four of the patients had free perforation and one had an abscess between the splenic flexure, spleen and surrounding organs, a yet unreported entity. All patients underwent emergency surgery including laparostomy with repeated explorations and lavages in two of them. The ethiology, pathophysiology and treatment of the condition are updated. A graphic algorithm for decision-making in appropriately dealing with stercoral perforation of the colon is proposed.
\end{abstract}

UNITERMS: Stercoral perforation, colon; peritonitis; resection; colectomy; diversion; scybala; intraoperative ortho grade colonic lavage; algorithm.

$\mathrm{S}$ tercoral perforation of the normal colon is an entity which has received relatively little attention in both the surgical and medical literature. Perhaps one of the reasons for this is the rarity of the condition. Nevertheless, stercoral perforation of the colon is important since it is associated with relatively high mortality approaching 35 percent for those managed surgically.'

This work was undertaken to report five new cases of stercoral perforation of the colon, to discuss this unusual condition with particular reference to its possible causation and to create a graphic algorithm for decision-making regarding the operative strategy.

\section{Address for correspondence:}

Julian Losanoff

P. O. Box, 159

Sofia - Bulgária - 1606

\section{PATIENTS AND METHODS}

Five patients with stercoral perforation of the normal colon were treated at the Department of Emergency Surgery of the Military Medical Academy of Sofia, Bulgaria, between 1975 and 1995. A summary of the principal findings in these patients is presented in Table 1.

Virtually all patients presented an acute, nonspectic abdomen condition. Past medical history revealed the following (Table 2). In all patients there was marked leucocytosis shifted to the left, marked fluid imbalance and arterial hypotony. An abdominal x-ray showed free air below the diaphragm in all but Case 2, in which emergency abdominal ultrasonography revealed a large abscess between the left colonic flexure and the spleen (Fig. 1). All patients underwent emergency laparotomies through xyphopubic incisions, with the suspicion of a hollow organ perforation. 
Table 1

Summary of principal findings in five patients with stercoral perforation of the normal colon.

\begin{tabular}{cccc}
\hline $\begin{array}{c}\text { Patient } \\
0\end{array}$ & Age, Sex & $\begin{array}{c}\text { Complaints at } \\
\text { admission } \\
\text { (hours) }\end{array}$ & Presentation \\
1 & $\begin{array}{c}\text { male } \\
75\end{array}$ & 52 & generized peritonitis \\
2 & $\begin{array}{c}\text { male } \\
45\end{array}$ & 102 & left upper quadrant peritonitis \\
3 & $\begin{array}{c}\text { female } \\
80\end{array}$ & 136 & generalized peritomitis \\
4 & $\begin{array}{c}\text { female } \\
76\end{array}$ & 92 & left lower quadrant peritomitis \\
5 & male & & \\
& 63 & 19 & - \\
\hline
\end{tabular}

In all five patients, the resected colonic segments were examined by a pathologist, both macroscopically and histologically. Maroscopically, the perforations had necrotic, inflammed edges; from inside the bowel, there was extensive necrosis of mucosa considerably larger than the site of the actual perforation.Microscopically, necrosis of perforation's edges was found (Fig. 2), with phlegmonous inflammation of the bowel wall of different degrees depending on the distance from the perforation (Fig. 3).

All patients who survived recieved life-long medications with mild aperients. None of them presented obstipation or complaints attributable to the presence of fecalomas in the colon.

\section{RESULTS}

The operative findings are listed in Table 3 .

In all patients, large fecalomas were found plugging the defects of the colonic walls, in all of them the colon was found to be filled with multiple fecalomas of different size from the ileocecal valve up to the rectal ampula. No associated intra-abdominal pathology was found, including all possible lesions that might contribute for a difficult gastrointestinal passage (adhesions, strictures, etc.)

The operations performed and the final outcome are presented in Table 4.

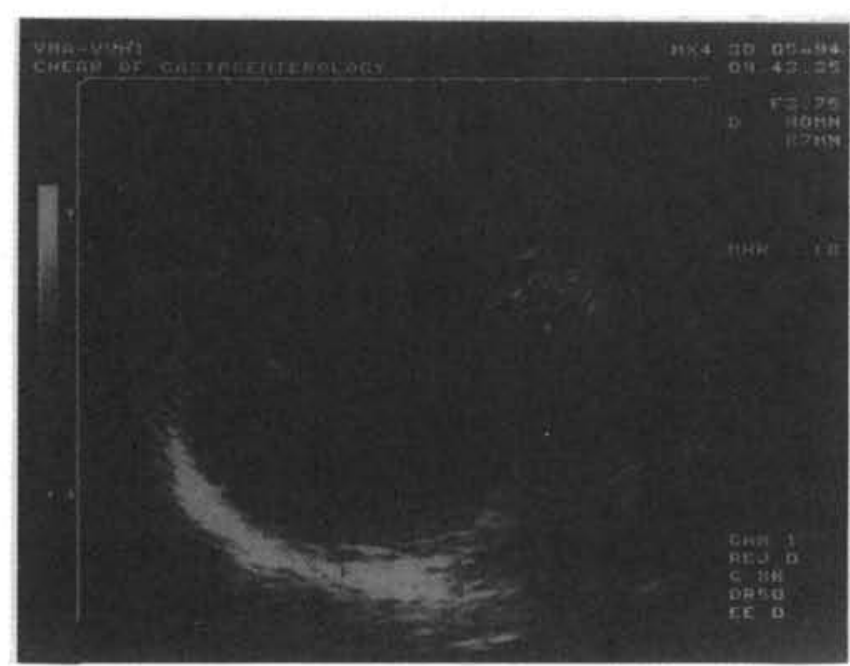

Figure 1 - Abdominal ultrasonography reveals a large abscess between the left colonic flexure and the spleen.

\section{DISCUSSION}

There is a general agreement in the current literature regarding the definition of stercoral perforation of the normal colon, namely "perforation of the bowel due to pressure necrosis from hard fecal masses". ${ }^{1.2}$ The morphologic changes of the bowel wall are typical: the perforation's edges are necrotic and inflammed; often a large fecaloma pluggs the defect (Fig. 4),corresponding in size to the perforation, and both macroscopically and microscopically there is ulceration of the mucosa with acute and chronic inflammation. ${ }^{3}$ All the patients from this series fulfilled the above-mentioned criteria so as to be undoubtedly included in this category.

To the best of our knowledge, only 67 cases of stercoral perforation of the normal colon have been described to date in the English language literature. ${ }^{1.4 .5}$ Patient's age range between 16 and 83 years (average, 59.3) with both sexes being almost equally affected. Typically, patients are elderly and inactive; as a rule, there is a long history of constipation or use of constipating agents such as anticholinergics, ganglionic blockers, tricyclic antidepresants, phenothiazine neuroleptics and steroids, but this does not seem universally valid for every case reported ${ }^{2.6}$ Longtanding obstipation has been ascribed to barium enema ${ }^{7}$ as well. Recently, stercoral perforation of the colon has been ascribed to intensive activated charcoal treatment. ${ }^{5}$ In this series, only one of the patients had no history of obstipation-causing long-term medication, but 


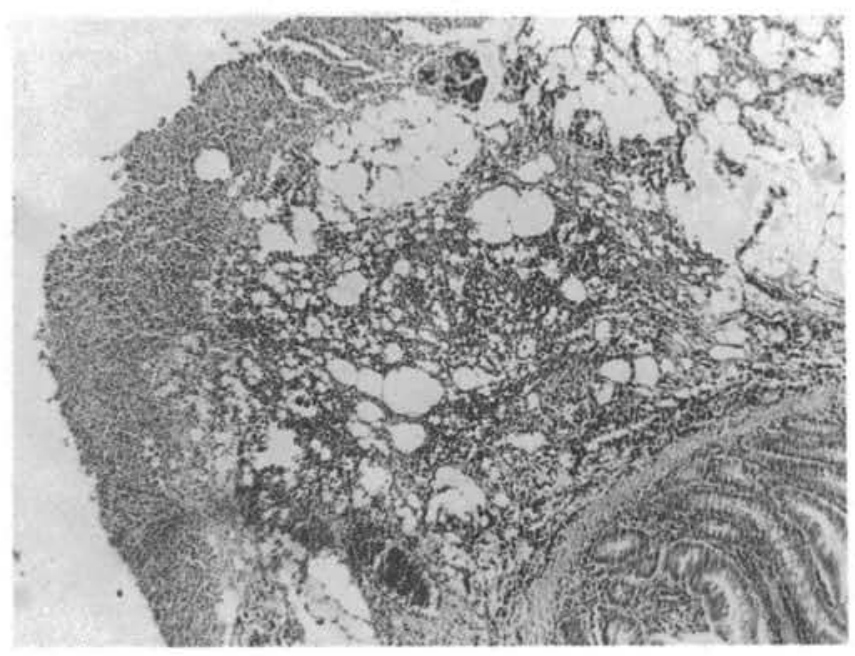

Figure 2 - Histology from the edges of a stercoral perforation displaying extensive necrosis and acute inflammatory changes. Hematoxylin \& eosin, x 44.

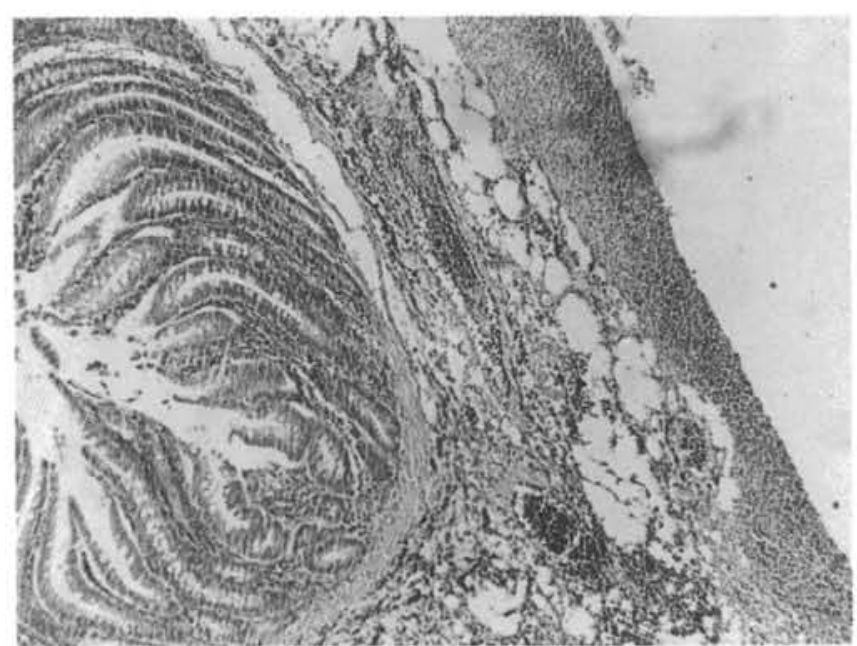

Figure 3 - Histology from the same specimen taken in the close proximity of the actual perforation's site and displaying transmural phlegmonous inflammation of the bowel wall. Hematoxylin \& eosin, $\times 44$. indeed, this patient had suffered from longstanding obstipation which might be the logical cause of his disease (Case 1). There was a history of such medication among the other patients (Table 2), as well as that of longstanding obstipation as the possible result of this medication.

Thus, we consider neglected constipation to be at least one of the major causes of stercoral perforation of the colon, as outlined by most of the other authors. ${ }^{1-3.5 .68-11}$ The avoidance of constipation, particularly among patients treated by constipative drugs, may eliminate, at least theoretically, the risks of stercoral perforation of the colon. Other factors thought to be implicated are hernias, haustrae, foreign bodies, or intestinal strictures. ${ }^{\text {." In }}$ fact, such pathology was not present among our patients, thus, we consider it to be of secondary importance. As exceptions, stercoral perforations can be found among young patients with spinal cord injury, or among patients

Table 2

Past medical history of the patient from the series.

\begin{tabular}{ccc}
$\begin{array}{c}\text { case } \\
\#\end{array}$ & $\begin{array}{c}\text { preceding long-term } \\
\text { medication and other illnesses }\end{array}$ & previous operations \\
\hline 1 & uninvestigated, untreated & \\
& obstipation /6 years/
\end{tabular}

2

3

4

5 obstipation / 8 years/ due to

8 years ganglionic blockers

therapy for hypertension

15 years of obstipation; 9 years of tricyclic antide-

presants treatment for de-

pression

11 years of obstipation; 6 years of anticholinergics

for allergic state

19 years of uninvestigated obstipation; 8 years of chroniodialysis for renal insufficiency; 4 years of phenothiazine neuroleptics appendectomy

22 years previously

hysterectomy

21 years previously bilateral nephroli-

thotomy, respective ly 10 and 3 years

previously 


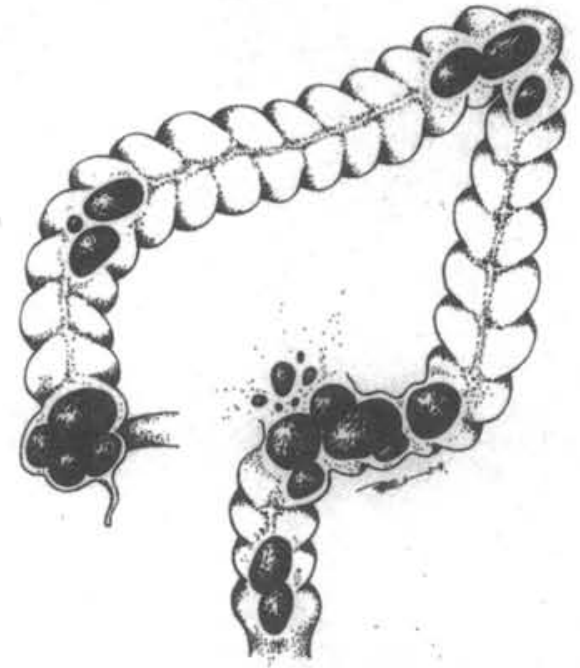

Figure 4 - Artist's drawing illustrating stercoral perforation the sigmoid colon with a large conglomerate of fecalomas plugging the defect. The entire colon is filled with multiple fecalomas, from the ileocecal valve up to the rectum.

without any history of longstanding obstipation. ${ }^{59}$ There are few reports of a perforation among patients with chronic renal failure or after renal transplantation. ${ }^{1.6}$ In our fourth case, both use of constipative agent and chronic renal failure may have contributed to the occurence of a stercoral perforation. Furthermore, it must be noted that the pathophysiological effects of both chronic renal failure and phenothiazine neuroleptics are similar and superimposing, leading rather "successfully" to obstipation and fecaloma formation.

Logically, stercoral perforation is obviously preceded by fecal impaction, defined as "collection of putty-like feces, that produces a hardened, concrete mass and blocks or impedes normal defecation".? Fecal impaction is considered to be especially dangerous when prolonged, ${ }^{12}$ and apart from alterations in colonic passage, it may lead to protean sequelae such as hydronephrosis ${ }^{7}$ or limb ischemia. ${ }^{13}$ Prompt recognition is thus extremely important as there is always a risk of the patient of developing life threatening conditions. In fact, all our patients were emergency cases, with perforations that already had occured. In none of them was there a history of manifested, prolonged fecal impaction, which is typical for most of the cases from the literature. ${ }^{1-3}$

In patients with stercoral perforation of the colon, acute abdomen and free gas below the diaphragm is the usual mode of presentation ${ }^{1.2 .6 .10}$, although, despite the history of longstanding obstipation, the condition is rarely suspected and patients are scheduled for emergency laparotomy for a hollow organ perforation. This was the case in all our patients, in none of whom was the correct diagnosis suspected preoperatively. Nevertheless, in a given elderly, inactive patient who has a long history of constipation, enough data might be present to suspect this entity. This, in addition to the positive findings of pneumoperitoneum and eventually fecaloma on plain film, should further contribute to one's suspicion.

Emergency surgery is undoubtetdly the only appropriate treatment for stercoral perforation of the colon. At operation, most perforations are found to be single (79 $\%$ ) and located on the antimesenteric aspect of the sigmoid and rectosigmoid (17\% and $30 \%$, respectively), followed by the cecum $(9 \%)$, transverse colon $(7 \%)$, descending colon $(5 \%)$, and splenic flexure $(2 \%)$."

Our Case 2 seems extremely interesting in respect to the lack of free perforation of the colon but of the presence of a well-established abscess filled with pus and fecalomas, to our knowledge, a yet unreported condition.

\begin{tabular}{|c|c|}
\hline & $\begin{array}{l}\text { Table } 3 \\
\text { Operative findings for five patients with stercoral } \\
\text { perforation of the colon. }\end{array}$ \\
\hline Case \# & Findings \\
\hline 1 & $\begin{array}{l}1.5 / 1 \mathrm{~cm} \text {. perforation of the cecum; phlegmona of the bowel } \\
\text { wall up to the midascending colon; generalized purulent } \\
\text { peritonitis }\end{array}$ \\
\hline 2 & $\begin{array}{l}2 / 2.5 \mathrm{~cm} \text {. perforation of the splenic flexure; abscess between } \\
\text { the lasser, stomach, spleen, and abdominal wall filled with } \\
\text { multiple fecalomas; serous peritonitis }\end{array}$ \\
\hline 3 & $\begin{array}{l}2 / 1 \mathrm{~cm} \text {. perforation of the midsigmoid; } 1 / 1.5 \mathrm{~cm} \text {. perforation of } \\
\text { the upper rectum; bowel phlegmona up to the midtransverse } \\
\text { colon; generalized feculent peritonitis }\end{array}$ \\
\hline 4 & $\begin{array}{l}4 / 3 \mathrm{~cm} \text {. perforation of the cecum; local bowel phlegmona } \\
\text { surrounding the perforation; generalized feculent peritonitis }\end{array}$ \\
\hline 5 & $\begin{array}{l}1.5 / 1.5 \mathrm{~cm} \text {. perforation of the midsigmoid; bowel phlegmona } \\
\text { up to the midtransverse colon; left lower quadrant purulent } \\
\text { peritonitis }\end{array}$ \\
\hline
\end{tabular}


Table 4

Operative procedures, outcome and duration of follow-up.

\begin{tabular}{llll}
\hline Case & Procedure & Outcome & Follow-up \\
\hline 1 & Right colectomy; double & Survived & 2.5 years; restoration \\
barrelled ileotransver- & & of bowel continuity, \\
& sostomy; intraoperative & & $\begin{array}{l}\text { colonoscopy } \\
\text { peritoneal and orthogra- }\end{array}$ \\
& & negative
\end{tabular}

de colonic irrigation

2

3

4

5

Resection of sigmoid, Survived
Hartmann's operation,
evacuation of pus with
drainage, orthograde
colonic irrigation

Left extended colectomy, Survived

splenectomy; end trans-

versostomy; distal sig-

moid mucous fistula,

drainage, intraoperative

peritoneal irrigation, and

orthograde colonic lavage

Resection of sigmoid;

Hartmann's operation;

milking of entire colon

through the stoma, lapa-

rostomy

Right colectomy, double-

barrelled ileotransver-

sostomy, milking of entire

colon, laparostomy

5
Died

Died

13 months; restoration

of bowel continuity,

colonoscopy

negative bowel restoration not
performed because
of poor risk; died of
myocardial infarction
2 years after
In our opinion, an abscess intimately adherent to the colon in a patient with longstanding constipation should also arize suspicion for a walled-of stercoral perforation.

The inflammatory process as a rule involves a whole segment of the colon ${ }^{2}$; the latter is often loaded with hard scibala. ${ }^{8.9}$ Furthermore, the necrotic changes on the inner surface of the bowel extended wide from perforation's edges. ${ }^{1.3}$ Among the cases described, all presented phlegmonous inflammation of a whole colonic segment, the colon of each was found to be loaded with multiple fecalomas, and the necrotic changes on the inner surface of the bowel extended considerably from the actual perforation's edges. All this should be always taken into consideration in order to prevent inadequate surgical treatment consisting of simple closure of the lesion or of a limited resection, without cleaning the residual colon from all the redundant fecal material.

The most frequently performed procedure having the highest survival rate is reported to be resection with colostomy. ${ }^{3,6.8}$ However, in order to escape the risk of a further perforation during the postoperative period, caused by retained fecalomas, intraoperative orthograde colonic 
Table 5

Graphic algorithm for decision making in managing patients with stercoral perforation of the colon.

Elderly patient with a history of longstanding obstipation or a history of long-term treatment with constipative agents, presenting acute abdomen

suspicion of stercoral perforation of the colon

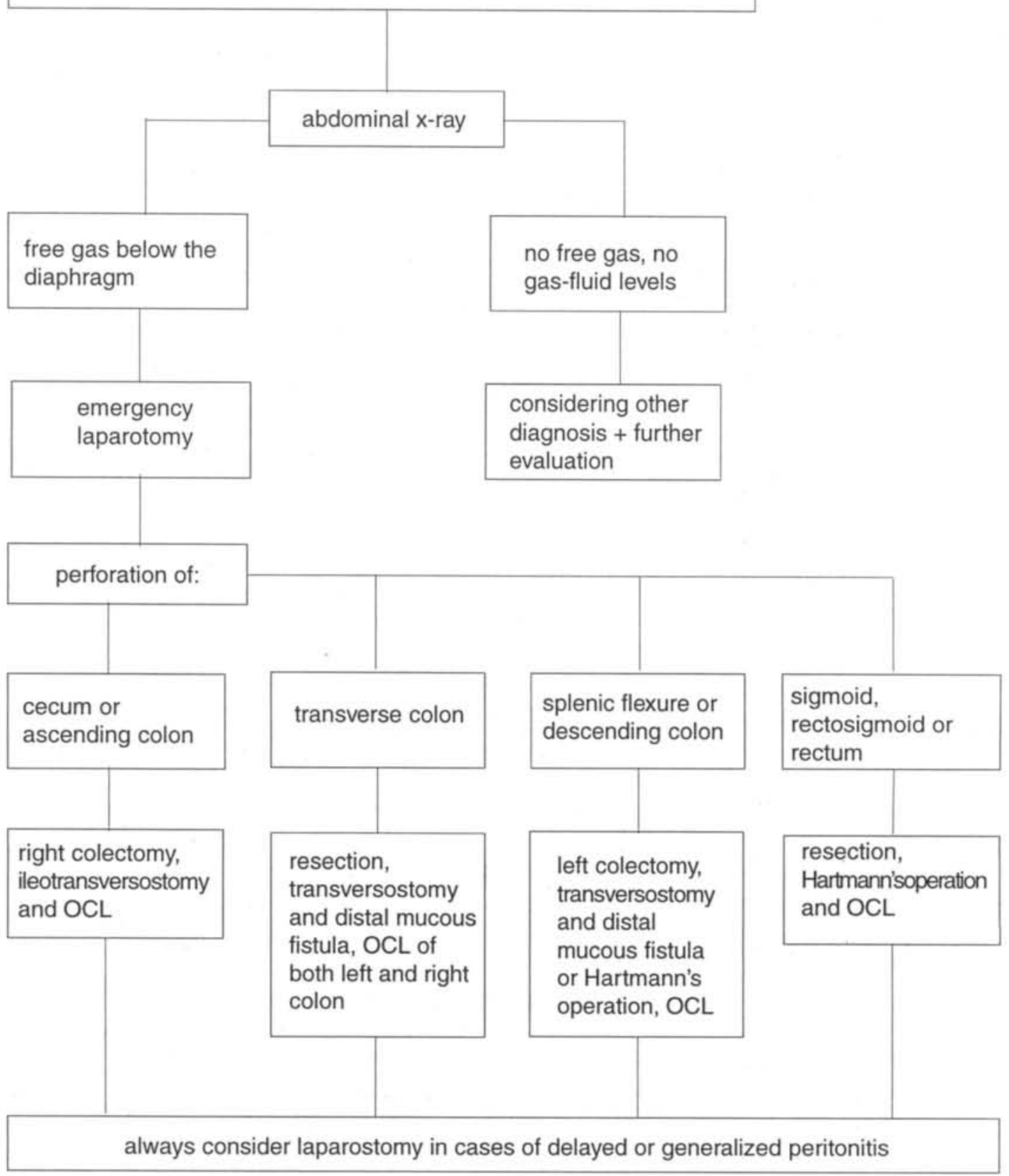

$\mathrm{OCL}$ - orthograde colonic lavage 
lavage must be included as an essential part of the complex surgical treatment. ${ }^{4}$ In two of our cases, milking of the colon was performed instead of lavage as there were no facilities for the latter. Nevertheless, the colon of all our patients was cleaned intraoperatively and no perforations occurred during the postoperative period nor were perforations discovered at autopsy in the two patients who died. This was due to their both their advanced age and degree of intoxication but, it is our opinion that, in advanced cases, laparostomy with repeat lavages and debridement may probably aid in achieving a higher survival figure.

Mortality is still unacceptably high in this condition, approaching $35 \%,{ }^{1-3}$ Possible reasons for the poor prognosis include an older patient age group, rapid clinical deterioration immediately following perforation, and well-established fecal peritonitis at the time of surgery. "The results can be improved only by rapid surgical intervention and aggressive resuscitation. Otherwise, longstanding obstipation should never be neglected but instead, actively treated. Interestingly, no uniform guidelines for surgical treatment have been outlined to date in the literature. Based on our experience with this series of five patients, and on the data from the literature, the following graphic algorithm can be proposed to contribute to more appropriately dealing with stercoral perforation of the colon from the surgical point of view (Table 5).

\section{RESUMO}

O trabalho apresenta uma série consecutiva de 5 pacientes com perfuração estercoral de cólon. Quatro pacientes apresentavam perfuraçāo livre e um deles um abscesso entre a flexāo esplēnica, baço e órgāos vizinhos, uma entidade ainda nāo relatada. Todos os pacientes foram submetidos à cirurgia de emergência, incluindo laparotomia com repetidas exploraçōes e lavagens em dois deles. A etiologia, fisiopatologia e tratamento dessa afecçäo foi revisada. É proposto um gráfico algaritmico para tomada de decisão em casos de perfuraçāo estercoral do cólon.

\section{REFERENCES}

1. Berardi RS, Lee SS, Chen HP, Stines GJ, Stercoraceous and spontaneous perforations of the colon. Int Surg 1987:72:235-40.

2. Casanova M, Ammann JF. Sterkorale Wandnekrose und Perforation des Colons. Chirurg 1985;56:189-91.

3. Claffey KB, Patton ML, Haith Jr LR, Germain TJ, Kerstein MD. Barium and fecal impaction: An unusual case of bilateral hydronephrosis. Am Surg 1995;61:709-13.

4. Durrans D, Redmont EJ, Marshman L. Stercoral perforation of the colon./letter/ Br J Surg 1991;78:1148.

5. Gekas P, Schuster MM. Stercoral perforation of the colon: Case report and review of the literature. Gastroenterology 1981;80:1054-8.

6. Gomez HF, Brent JA, Munoz DC, Mimmack RF, Ritvo J, Phillips S, McKinney P. Charcoal stercolith with intestinal perforation in a patient treated for amitriptyline ingestion. J Emerg Med 1994;12:57-60.
7. Hoballah JJ, Chalmars RTA, Sharp WJ, Stokes JB, Corson JD. Fecal impaction as a cause of acute lower limb ischemia. Am J Gastroenterol 1995;90:2055-7.

8. Huttunen R, Heikkinen E, Larmi TK. Stercoraceous and idiopathic perforations of the colon. Surg Gynecol Obstet 1975;140:756-60.

9. Lyon DC, Sheiner HJ. Idiopathic rectosigmoid perforation.Surg Gynecol Obstet 1969;128:991-1000.

10. Poos RJ. Kolonperforation. In: Beger HG, Kern E (eds). Akutes Abdomen. Stuttgart-New York. Thieme, 1987, 272-5.

11. Serpell JW, Nicholls RJ. Stercoral perforation of the colon. Br J Surg 1990;77:1325-9.

12. Soravia C, Baldi A, Kartheuser A, Mourad M, Kestens PJ, Detry R, Squifflet JP. Acute colonic complications after kidney transplantation. Acta chir belg 1995;95:157-61.

13. Thayer WR, Denucci T. Stercoral ulcerations and perforations of the colon. In: Kirsner JB, Shorter RG (eds). Diseases of the colon, rectum, and anal canal. Baltimore, Williams \& Wilkins, 1988, 572-3. 